\title{
Diagnostic and Therapeutic Endoscopy in the Biliary Tract and Pancreas
}

\author{
Ian C Roberts-Thomson and Nam Q Nguyen \\ Departments of Gastroenterology and Hepatology \\ The Queen Elizabeth Hospital and Royal Adelaide Hospital, Adelaide \\ Australia
}

\section{Introduction}

The development of fiberoptic endoscopes between 1960 and 1970 was an important event in the evolution of the specialty of gastroenterology. Several of these endoscopes had sideviewing or oblique-viewing lenses that provided reasonable views of the ampulla of Vater. Cannulation of the ampulla and retrograde pancreatography was first reported in 1968 (McCune et al., 1968). Subsequent developments largely occurred in Japan and led to a more detailed description of endoscopic retrograde cholangiopancreatography (ERCP) in 1970 (Takagi et al., 1970). This was soon followed by a description of endoscopic sphincterotomy by independent groups in Germany and Japan in 1974 (Classen \& Demling, 1974; Kawai et al., 1974).

By the mid-1970's, ERCP had been adopted by several major centers but was not widely accepted because it was perceived as either "too difficult" or "too prone to complications". The major complication was that of pancreatitis. This occurred in up to $10 \%$ of patients and was associated with significant morbidity and at least some mortality. Even today, risks for pancreatitis remain significant despite a large number of studies that have attempted to reduce the risk using procedural modifications or various drugs.

The next milestone in therapeutic ERCP was a description of endoscopic stents for malignant biliary obstruction (Soehendra and Reynders-Frederix, 1979). This was followed by a description of therapeutic procedures in the pancreas including stents for strictures in the main pancreatic duct, endoscopic extraction of pancreatic stones, endoscopic drainage of pancreatic pseudocysts and endoscopic stents for pancreatic fistulae and pancreatic ascites. By the mid-1980's, ERCP had been widely adopted and was recognized as the therapeutic procedure of choice for bile duct stones, particularly after cholecystectomy.

Developments since 1990 include the use of self-expanding metal (metallic) stents for malignant biliary obstruction and the development of ultrathin endoscopes for direct cholangioscopy and pancreatoscopy. Although endoscopic ultrasound (EUS) was first described in 1976 (Lutz and Rosch, 1976), it has only recently been widely applied to pancreatic and biliary disorders, largely because of technical developments including the opportunity for tissue sampling using fine-needle aspiration.

The purpose of this report is to provide an outline of diagnostic and therapeutic procedures in the biliary tract and pancreas. We will also include endoscopic procedures currently under evaluation that might have a role in future therapy. 


\section{Diagnostic procedures}

\subsection{Historical and technical aspects}

Prior to 1970, options for cholangiography included intravenous cholangiography and percutaneous transhepatic cholangiography. The former was unhelpful in the presence of jaundice and, in the absence of jaundice, had a relatively high frequency of false positive and false negative results. Percutaneous cholangiography was largely restricted to patients with jaundice and was usually performed as a pre-operative procedure because of the risk of a bile leak. Although ultrasound (US) and computed tomography (CT) scans were introduced in the late 1970's and early 1980's, respectively, these investigations did not have a major impact on the frequency of diagnostic procedures until the late 1980's. Magnetic resonance imaging (MRI) scans were introduced in the late 1990's but have only become widely available in the past decade.

Surprisingly, the endoscopes and ancillary equipment necessary for ERCP were largely developed in the 1970's. The principle was placement of a catheter in the orifice of the ampulla followed by the injection of contrast into the desired duct. The procedure was performed using intermittent fluoroscopy and radiographs were taken of appropriate images. In most patients, the desired duct is the bile duct but, unfortunately, it is often easier to outline the main pancreatic duct. Because of this, various techniques have been used to promote biliary cannulation including the use of a partly-opened papillotome, use of appropriately placed guide-wires and, under some circumstances, use of small endoscopic incisions (pre-cuts) to facilitate bile duct cannulation. The latter technique should probably be restricted to experts because of higher risks for pancreatitis (Hochberger et al., 2003). Endoscopic and radiologic images of selected biliary and pancreatic disorders are shown in figures 1 and 2 .
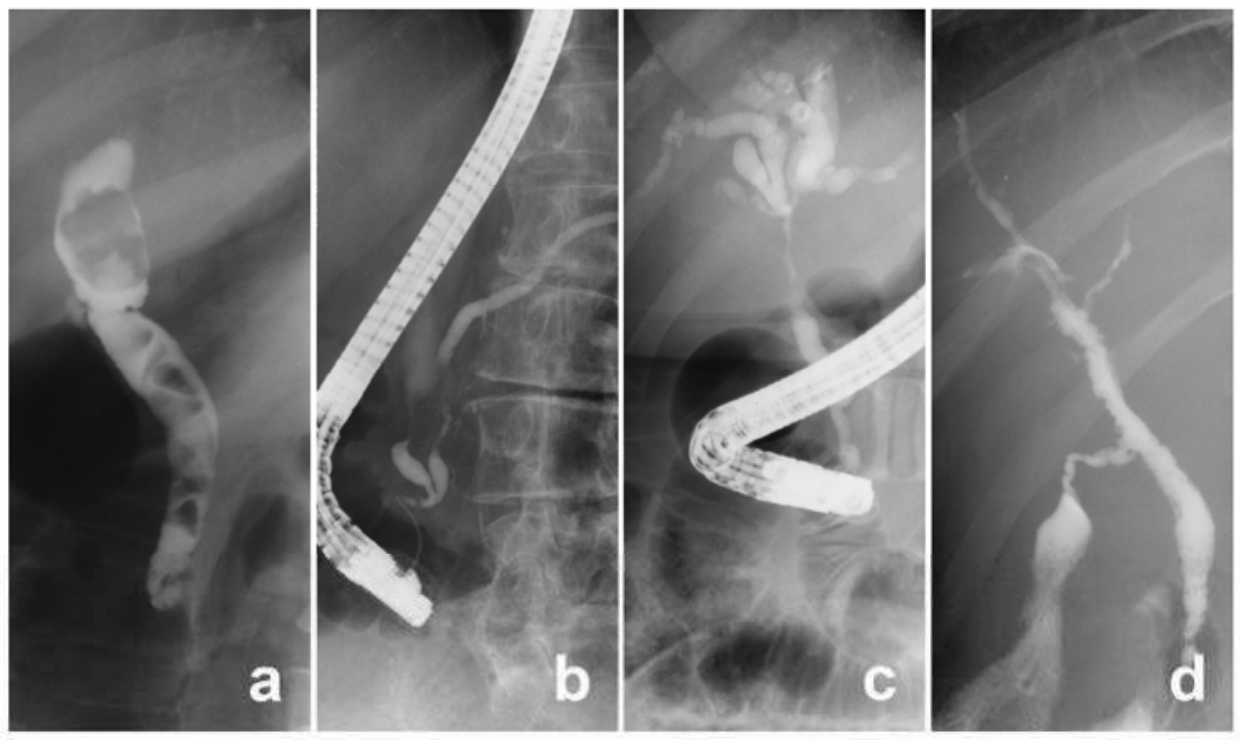

Fig. 1. Miscellaneous cholangiograms. (a) Multiple bile duct stones. (b) Carcinoma of the head of pancreas with strictures in the lower bile duct and main pancreatic duct. (c) Bile duct cancer involving the common hepatic duct. (d) Typical features of sclerosing cholangitis. 


\subsection{Bile duct stones}

The preferred diagnosis for both patient and endoscopist is that of choledocholithiasis. In this setting, cannulation of the ampulla is often relatively easy and stones are outlined as mobile filling-defects within the bile duct. The cystic duct and gallbladder can also be outlined. For most of these patients, the sequence of investigations is an upper abdominal ultrasound study followed by ERCP. For patients with a probability of bile duct stones of $80 \%$ or less, additional useful information may be obtained by magnetic resonance cholangiopancreatography (MRCP) or EUS.

\subsection{Ampullary, biliary and pancreatic neoplasms}

Duodenal endoscopy is helpful for at least some neoplasms. In particular, most ampullary neoplasms can be diagnosed at duodenal endoscopy and confirmed by biopsy. Furthermore, approximately $5 \%$ of biliary and pancreatic cancers infiltrate or ulcerate into the second part of the duodenum and can also be confirmed by biopsy. Typical pancreatic cancer with obstructive jaundice (but without duodenal infiltration) results in strictures in both the main pancreatic duct and bile duct. This is usually associated with proximal dilatation of both ducts. In the absence of jaundice, the typical appearance is a stricture in the main pancreatic duct with proximal dilatation or complete obstruction of the duct. Similarly, in bile duct cancer, the typical appearance is an irregular biliary stricture that is normally associated with proximal dilatation including dilatation of intrahepatic ducts.

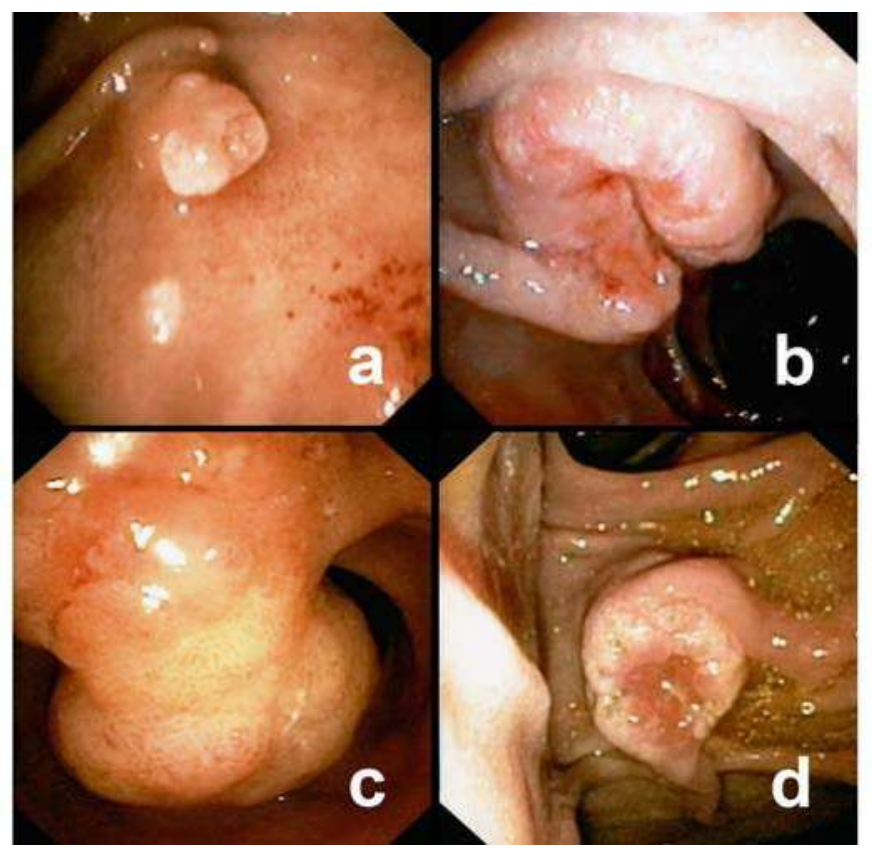

Fig. 2. Neoplasms of the ampulla of Vater. (a) Tiny adenomas of the ampulla associated with familial adenomatous polyposis. (b) Neuroendocrine neoplasm (carcinoid tumor) of the ampulla. (c) Large polypoid carcinoma of the ampulla. (d) Small ulcerated carcinoma of the ampulla. 
At a clinical level, it may be difficult to differentiate pancreatic cancer from autoimmune pancreatitis and some cases of chronic pancreatitis. Although malignant biliary strictures without pancreatic duct strictures are usually caused by bile duct cancer $(60 \%-70 \%)$, alternative possibilities include gallbladder cancer that spreads to the bile duct and metastatic cancer or lymphoma in subhepatic lymph nodes. Rarely, the differential diagnosis can also include benign biliary strictures such as post-operative strictures and sclerosing cholangitis.

\subsection{Pancreatitis and its complications}

Prior to the mid-1980's, ERCP was widely used for the diagnosis of non-calcific chronic pancreatitis and for the diagnosis of complications of pancreatitis such as pseudocysts and biliary obstruction. The diagnosis of chronic pancreatitis largely rested on radiological changes in the main pancreatic duct and side-branches. In relation to pseudocysts, at least $70 \%$ could be outlined at pancreatography although there was a small risk of conversion of a pseudocyst into a pancreatic abscess. Today, modern imaging techniques have largely replaced pancreatography for the diagnosis of most pancreatic disorders. However, pancreatography may still have a role in uncommon disorders such as idiopathic relapsing pancreatitis and pancreatic ascites (Petersen, 2002).

\subsection{Role of endoscopic ultrasound}

EUS is being increasingly used to enhance the diagnostic accuracy of traditional ERCP. Arguably, the most important development is the contribution of fine-needle aspiration to the histological or cytological diagnosis of various neoplasms. However, it is also being used to confirm the diagnosis of bile duct stones, to diagnose non-calcific chronic pancreatitis and to delineate the size and spread of various neoplasms (Figure 3a-e). In relation to bile duct stones, endoscopic ultrasound may be more sensitive than ERCP and MRCP for the detection of small stones, $<5 \mathrm{~mm}$ in diameter (Kondo et al., 2005). It may also have a role in acute biliary pancreatitis where bile duct stones can pass spontaneously into the duodenum after induction of pancreatitis.

Endoscopic ultrasound is also being used for the diagnosis of mild chronic pancreatitis that is not associated with ductal dilatation, calcification or cysts. Various EUS criteria have been developed to reflect changes in pancreatic parenchyma that may be more sensitive than ductal changes at ERCP (Gleeson and Topazian, 2007). For pancreatic neoplasms, EUS provides high-resolution images of the pancreas that can detect lesions as small as $2-3 \mathrm{~mm}$ in diameter. Similar results have been obtained for bile duct cancer although the quality of images for distal tumors is superior to that for proximal tumors.

\subsection{Tissue sampling}

Although radiologic appearances are highly associated with various cancers, some surgeons and most oncologists are reluctant to embark on major therapies without histologic confirmation. As noted above, a minority of tumors can be identified at duodenal endoscopy and confirmed by duodenal biopsy. For the majority, options include percutaneous fine-needle aspiration with cytology and the histologic or cytologic evaluation of tissue taken at endoscopy. One endoscopic option is the cytologic evaluation of fluid aspirated from the main pancreatic duct or bile duct (Tanaka and Kida, 2009). In general, results from these studies have been disappointing. A variation is that of brushing cytology 
of these strictures. This has been helpful in some studies but results in bile duct cancer have been disappointing, perhaps because many cancers are sclerotic with only a minority of malignant cells (Tanaka and Kida, 2009). Another endoscopic approach is to take biopsies of the stricture using routine or modified biopsy forceps. This can be technically demanding but, when biopsies are obtained, confirmation of cancer has been reported in approximately $50 \%$ of cases (Howell et al., 1996).

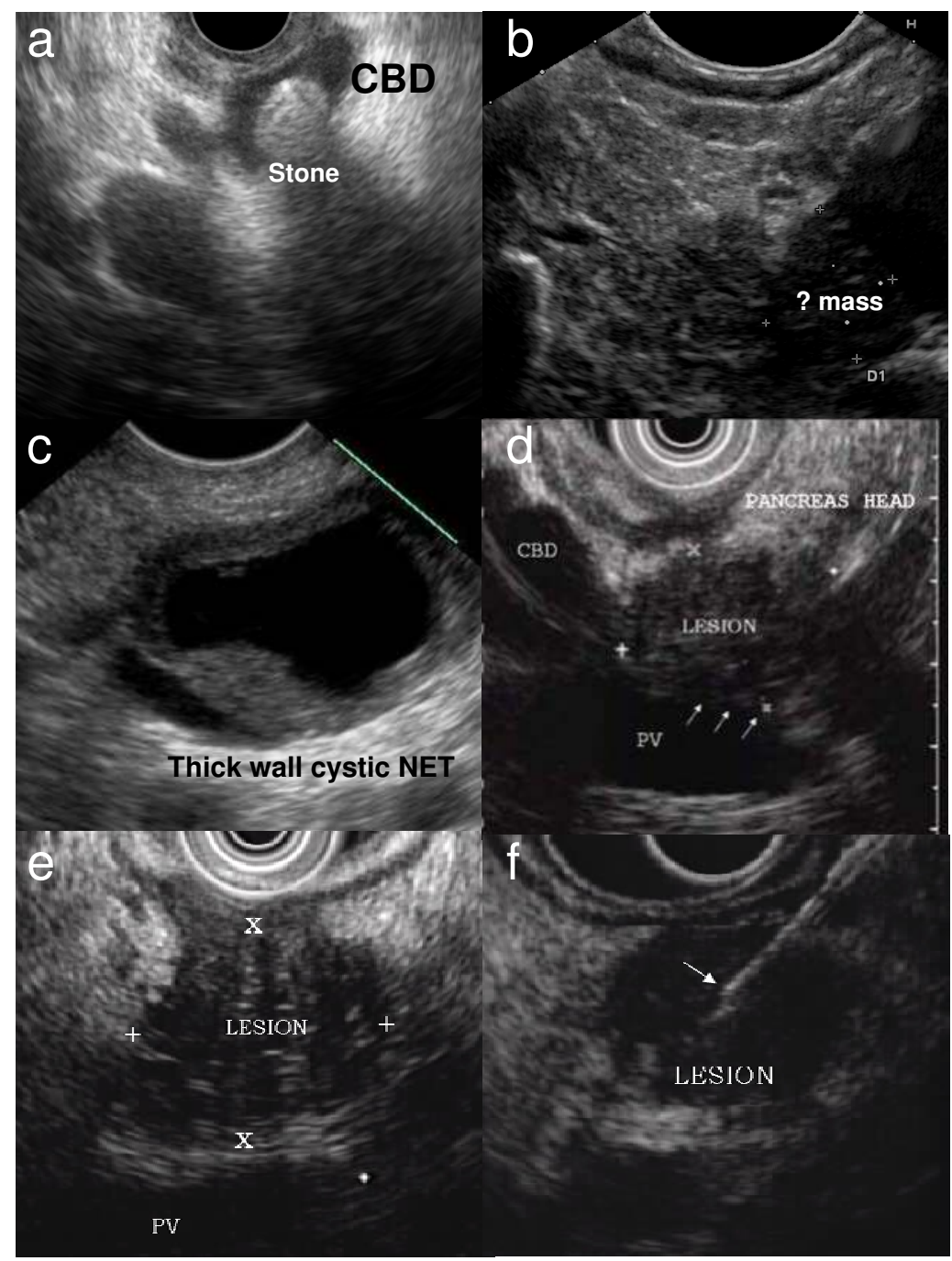

Fig. 3. EUS images demonstrating the presence of (a) a CBD stone, (b) a possible mass in a patient with pancreatic parenchymal changes consistent with chronic pancreatitis, (c) a cystic neuroendocrine tumor (NET), (d) a locally advanced pancreatic cancer invading the portal vein and (e \& f) biopsy of a pancreatic lesion using EUS with fine-needle aspiration. 
Currently, the procedure with the highest sensitivity for cancer is cytologic evaluation of fine-needle aspirates taken during endoscopic ultrasound (Figure $3 \mathrm{f}$ ). In one randomized study in patients with suspected pancreatic cancer, rates for the detection of cancer in fineneedle aspirates were higher for specimens taken by endoscopic ultrasound (84\%) than for specimens taken percutaneously under ultrasound or CT control (62\%) (Horwhat et al., 2006). Similar results have been obtained for confirmation of bile duct cancer although the yield was significantly higher in distal cancer $(81 \%)$ than in proximal cancer $(59 \%)$ (Mohamadnejad et al., 2011).

\subsection{Diagnostic cholangiopancreatoscopy}

Although the first cholangioscope was developed over three decades ago, use of this technology was limited because of cost, endoscope fragility and the need for two experienced endoscopists to operate the "mother" and "daughter" scopes. However, interest in this technology has been reawakened by recent developments that include singleoperator cholangiopancreatoscopy with facilities for forcep biopsy, the development of video endoscopes for cholangiopancreatoscopy and the development of balloon-facilitated ultrathin endoscopes that can be passed into the duct systems (Nguyen et al., 2009).

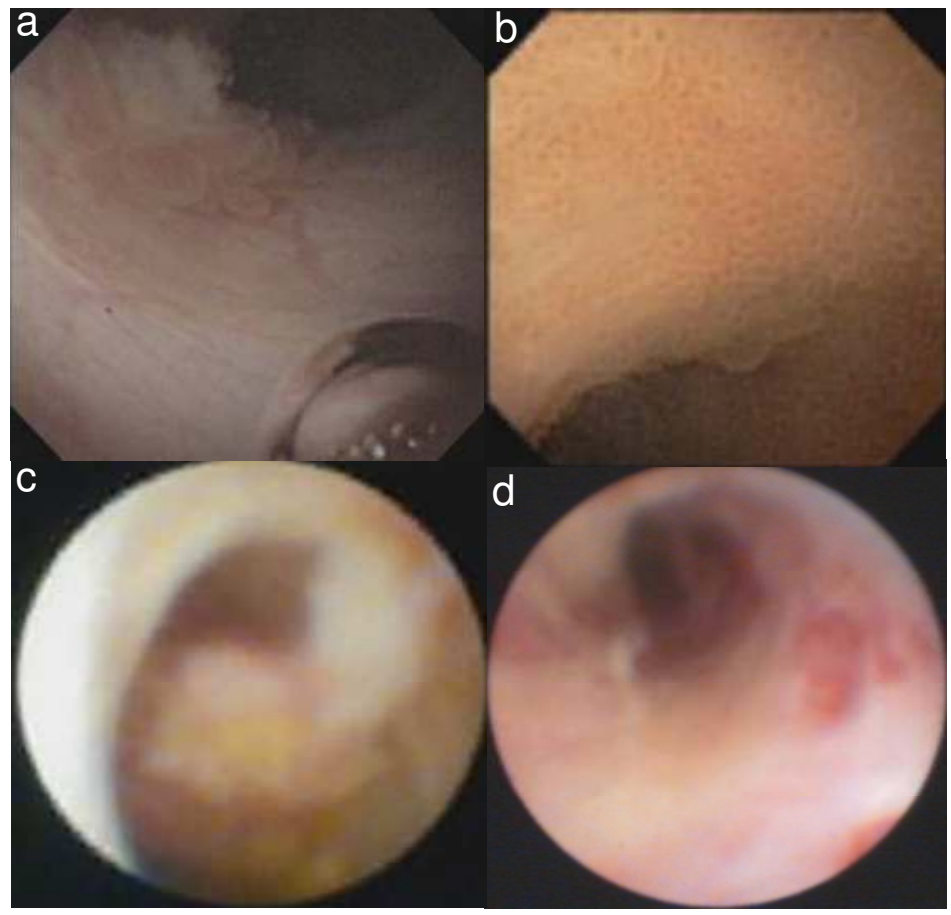

Fig. 4. Video (a \& b) and SpyGlass (c \& d) cholangiopancreatoscopy images showing (a) an early superficial papillary bile duct lesion, (b) the typical fish-egg like lesions of intraductal papillary mucinous neoplasia carpeting the bile duct, (c) an obstructing polypoid cholangiocarcinoma of the right hepatic duct and (d) occult malignancy in a patient with primary sclerosing cholangitis. 
The aim of cholangiopancreatoscopy is the direct visualization of ductal strictures, particularly in the bile duct. The appearance of these strictures often facilitates the differentiation of benign from malignant disorders (Figure 4). Video ductal endoscopes provide images of high quality but, at present, do not permit endoscopic biopsy. In contrast, the SpyGlass system incorporates a fiberoptic probe with somewhat inferior images but, importantly, provides access for endoscopic biopsy. Histological confirmation of cancer can be achieved in $70-80 \%$ of patients (Nguyen et al., 2009).

\section{Endoscopic interventions}

\subsection{Sphincterotomy and stone extraction}

The contemporary technique of endoscopic sphincterotomy is remarkably similar to that described by Classen and Demling in 1974. The principles include selective cannulation of the bile duct with the papillotome, retraction of a diathermy wire to create a bow and passage of a current across the diathermy wire to make an endoscopic incision. This increases the diameter of the bile duct orifice from a pinhole to $2-5 \mathrm{~mm}$. Prior to 1975 , bile duct stones were initially left to pass spontaneously into the duodenum. However, within 2 years, stone extraction techniques had been described including the use of wire (Dormia) baskets and catheters with peripheral balloons (Figure 5, a-c).

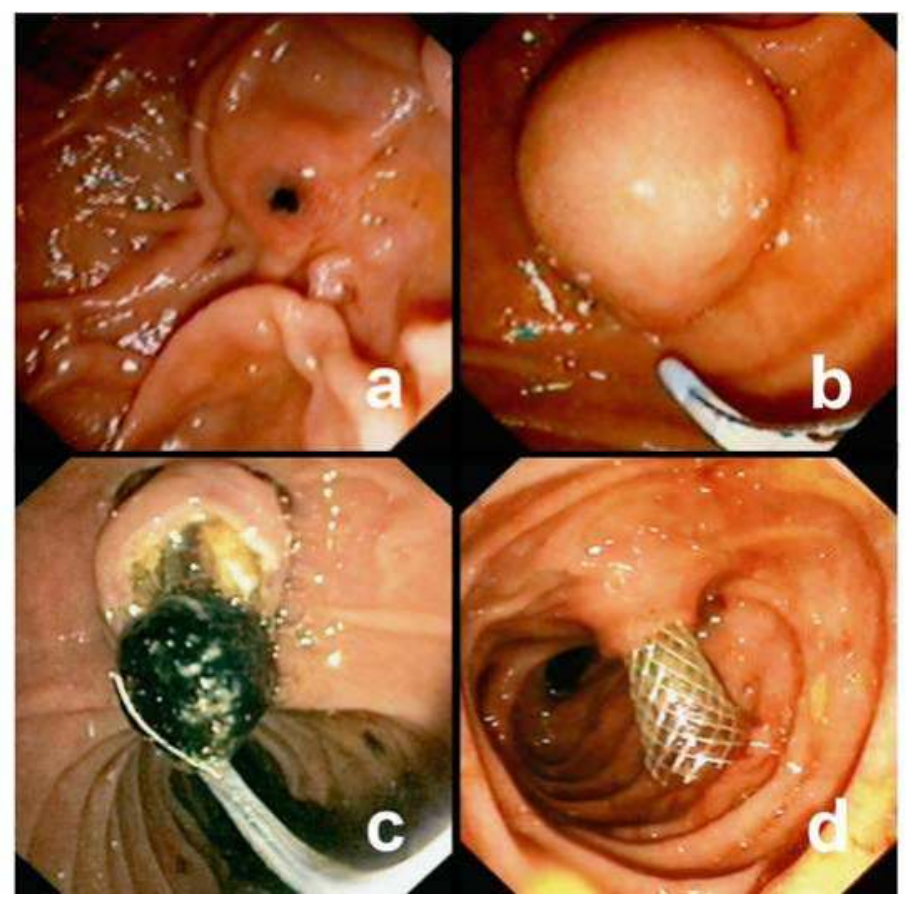

Fig. 5. Endoscopic features relevant to therapeutic endoscopy. (a) Impacted pigmented calculus in the orifice of the ampulla. (b) Bulbous papilla caused by an impacted calculus. (c) Extraction of a calculus after endoscopic sphincterotomy. (d) Metallic stent projecting into the duodenum in a patient with pancreatic cancer. 
The above techniques have been remarkably successful when performed by experienced endoscopists. For example, most endoscopists now claim rates for successful extraction of stones of between 90 and 95\% (Safrany, 1978; Roberts-Thomson, 1984). However, difficulties may arise with large stones, impacted stones, ampullary orifices located within duodenal diverticula and bile duct stones in patients who have previously been treated with a Billroth II gastrectomy. The management of large stones often includes fragmentation using reinforced crushing baskets. If endoscopic extraction of stones fails during the first attempt, one option is placement of a plastic stent around the stone (to minimize the risk of cholangitis) and a second attempt at stone extraction after 2-4 weeks. Another option is direct cholangioscopy with visualization of the stone and fragmentation with intraductal shockwave (electrohydraulic or laser) lithotripsy. In patients who have previously had a Billroth II gastrectomy, difficulties may arise with negotiation of the afferent loop, selective cannulation of the bile duct and appropriate orientation of the papillotome.

The complications of endoscopic sphincterotomy have been widely discussed and include pancreatitis $(5 \%)$, significant bleeding from the margins of the incision $(2 \%)$ and duodenal perforation $(<1 \%)$. Mortality rates within 30 days are approximately $0.2 \%$ but only a minority of deaths are directly related to the procedure (Freeman et al., 1996; Cooper and Slivka, 2007).

\subsection{Endoscopic stents}

Options for patients with malignant strictures of the bile duct include radical surgery with the potential for cure, palliative surgery with a biliary bypass procedure and the endoscopic placement of a biliary stent. In patients scheduled for curative surgery, stents are sometimes used to relieve jaundice prior to the operation although this appears to be unnecessary in patients with a serum bilirubin of $<250 \mu \mathrm{mol} / 1$ (van der Gaag et al., 2009). In patients who require palliative procedures, the choice of stent versus biliary bypass is often determined by factors such as age and perceived operative risk. For example, older patients with more complex medical problems are more likely to be treated with stents while younger patients with fewer operative risks are more likely to be treated by biliary bypass. An additional issue is the presence of malignant infiltration of the duodenum that may result in duodenal obstruction. In this setting, options include biliary and duodenal stents or a biliary bypass procedure with a gastroenterostomy.

The first endoscopic stents were composed of plastic and were $7 \mathrm{~F}-8 \mathrm{~F}$ in diameter. Subsequently, endoscopes with larger working-channels were introduced that permitted the insertion of larger stents (10F). Most patients treated with conventional 10F stents show improvement or resolution of jaundice but stents become obstructed by biofilms after 2-5 months. Attempts to prolong stent patency have included use of different plastic materials, changes in stent design and longer-term treatment with drugs such as antibiotics and ursodeoxycholic acid. These measures have been largely ineffective in clinical trials. Because of this, stents are usually changed electively at intervals of about 3 months in those patients who require stenting for prolonged periods.

Self-expanding metal stents (Figure 5d) are now widely used for palliation in patients with malignant obstructive jaundice (Chun et al., 2010). These stents expand to a diameter of approximately 30F $(10 \mathrm{~mm})$ and usually remain patent for 6-9 months. However, metal stents can still obstruct because of biofilms, the accumulation of biliary debris, tumor growth through the wire mesh or tumor growth above the stent. Additional issues are the higher cost of metallic stents and an inability to remove the stent if there are complications 
such as obstruction or cholangitis. However, these complications can usually be managed by insertion of a second metal stent or by the insertion of a plastic stent within the metal stent. Another approach that may delay tumor ingrowth is use of a "covered" metal stent although a potential problem is greater formation of biofilms. One practical approach is to use plastic stents in patients whose survival seems likely to be short and metal stents in patients with a predicted survival of more than 3-6 months.

\subsection{EUS assisted therapeutic endoscopy}

Access to the biliary system at ERCP can fail in 1-5\% of patients. Reasons include large duodenal diverticula and a sphincter of Oddi that is either thickened or deformed. In this setting, one option is percutaneous cholangiography with passage of a guidewire into the duodenum. Another option is to use EUS to direct a 19F needle into the bile duct and then pass a guidewire into the duodenum. EUS with passage of a guidewire into the duodenum has also been used to facilitate cannulation of an obstructed main pancreatic duct. Success rates with these techniques are higher if ducts are dilated (Kim et al., 2010).

\subsection{Cholangioscopy assisted therapeutic endoscopy}

If difficulty is encountered with passage of a guidewire through a tight biliary stricture, it may be helpful to perform cholangioscopy with passage of a guidewire under direct vision. There are also reports of the use of cholangioscopes for the ablation of biliary tumors using either lasers or argon plasma coagulation (Nguyen et al., 2009).

\subsection{Endoscopic ampullectomy}

Neoplasms of the ampulla of Vater have traditionally been managed by laparotomy with local or more radical resections (Whipple's procedure). However, at least some neoplasms are now being managed by endoscopic resection, usually after staging by EUS. The technique of ampullectomy is similar to that for removal of larger polyps and includes elevation of the base with saline (with or without adrenaline) and resection using a polypectomy snare (Figure 6). In expert hands, successful eradication of adenomas has been reported in up to $85 \%$ of patients (Nguyen and Binmoeller, 2010). However, it may be inappropriate to attempt endoscopic resection for adenomas $>4-5 \mathrm{~cm}$ in diameter because of higher risks for complications and higher rates of incomplete resection.

\subsection{Endoscopic therapy for pancreatic pseudocysts, pancreatic necrosis and pancreatic ascites}

Pancreatic pseudocysts can complicate both acute and chronic pancreatitis. The majority of pseudocysts are asymptomatic and resolve spontaneously. A drainage procedure is only indicated for pseudocysts that are symptomatic, infected, rapidly enlarging or causing obstruction of the gastrointestinal tract or neighbouring structures such as the biliary tract. An additional indication is the presence of cysts $>10 \mathrm{~cm}$ in diameter because of the risk of spontaneous rupture or hemorrhage. Options for the drainage of pseudocysts include open or laparoscopic surgery, percutaneous drainage under US or CT guidance and endoscopic drainage with help from EUS. Unfortunately, these approaches have not been compared in randomized trials. Because of this, the choice of procedure is often determined by the availability of EUS and local expertise (Nguyen and Binmoeller, 2009). Percutaneous or endoscopic drainage is usually contraindicated for 
cysts that are multi-loculated or for cysts with solid components or other features suspicious of neoplasia.

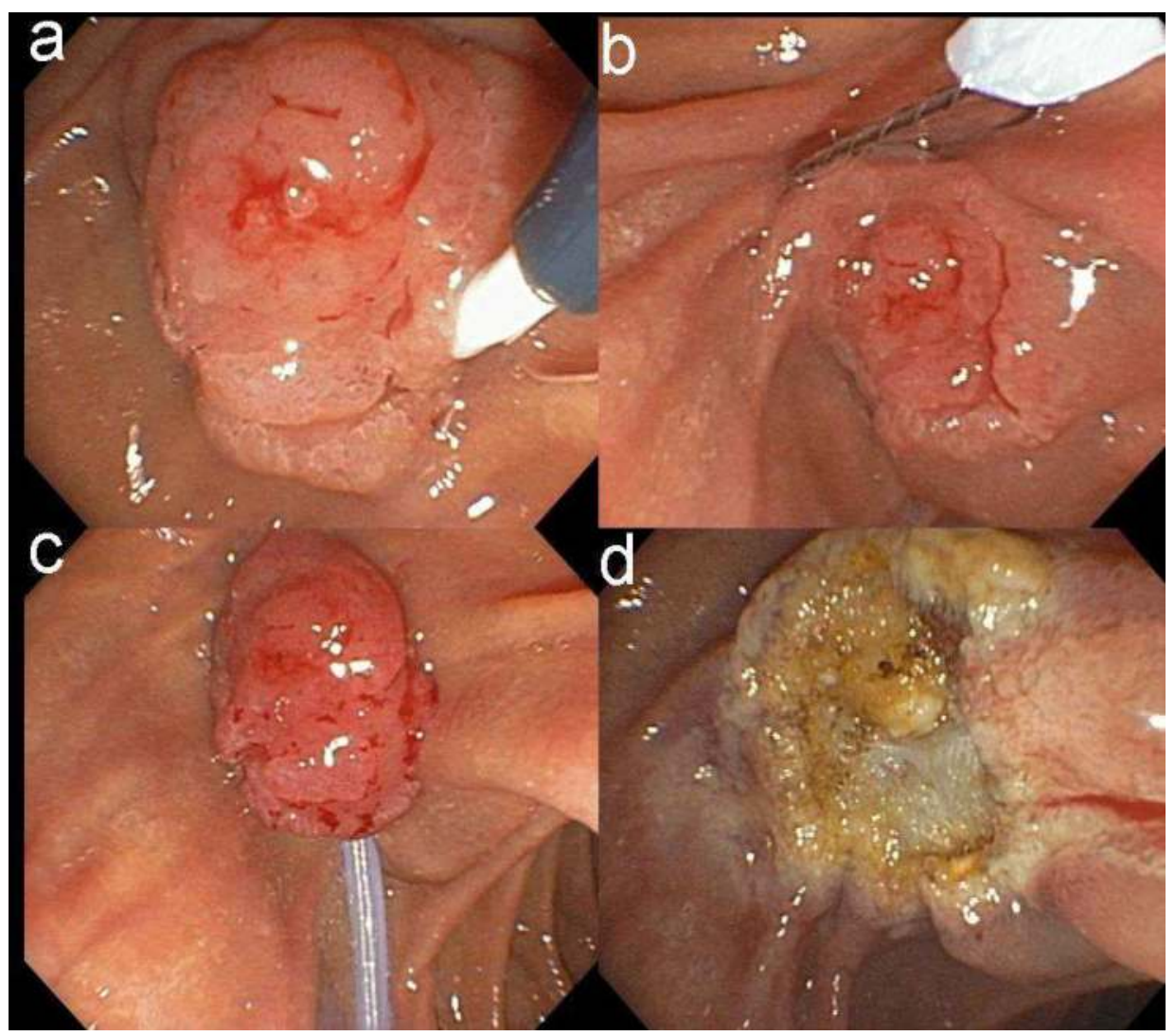

Fig. 6. En bloc endoscopic ampullectomy showing (a) an ampullary adenoma, (b \& c) snaring of the adenoma in its entirety, (d) appearance of the area after resection.

Endoscopic approaches have also been used for the drainage of pancreatic fluid collections. These may develop because of severe pancreatitis or because of the development of pancreatic ascites. The latter is usually due to spontaneous rupture of a pseudocyst but, in a minority of cases, duct disruption can occur because of pancreatic necrosis. The endoscopic management of these patients needs to be individualized but may involve transpapillary drainage, transmural drainage or combined approaches. In this heterogeneous group, successful outcomes can be achieved in approximately $80 \%$ of patients although there are several potential complications including bleeding, perforation, infection and stent migration (Mergener and Kozarek, 2003).

\subsection{Endoscopic therapy for chronic pancreatitis}

Some patients with chronic pancreatitis have chronic pain or frequent episodes of pain that result in recurrent admissions to hospital or the use of escalating doses of narcotic 
analgesics. In this setting, management options include pancreatic surgery, endoscopic therapy and various measures for pain including a celiac plexus nerve block. At least one mechanism for pain is a degree of obstruction of the main pancreatic duct with elevated intraductal pressures. Because of this, some surgical and endoscopic approaches have endeavoured to relieve duct obstruction by removing stones or dilating or bypassing duct strictures. In calcific chronic pancreatitis, endoscopic removal of stones is difficult and many patients are treated by extracorporeal shockwave lithotripsy prior to endoscopic therapy. The latter usually involves biliary and pancreatic sphincterotomy, dilatation of strictures and extraction of stones in the main pancreatic duct. Responses to endoscopic therapy have been variable but most studies report improvement in pain in $30-70 \%$ of patients. Although these endoscopic results may be inferior to results from pancreatic surgery (Díte et al., 2003; Cahen et al., 2007), endoscopic therapy can be repeated with a relatively low risk for complications.

\section{Future developments}

Preliminary studies are evaluating the possibility of endoscopic therapy for solid and cystic neoplasms of the pancreas. One promising approach is EUS-guided ethanol lavage (with or without paclitaxel injections) for the treatment of cystic tumors of the pancreas (DeWitt et al., 2011; Oh et al., 2011). This appears to result in resolution of cysts in up to $70-80 \%$ of patients. Innovative approaches have also been taken for the treatment of locally advanced pancreatic cancer. These include EUS-guided injections of chemotherapeutic drugs and various immunomodulatory preparations including allogenic mixed lymphocyte cultures (Cytoimplants), adenovirus vectors carrying the tumor necrosis factor-alpha gene and attenuated adenoviruses that preferentially replicate in malignant cells. There are also on-going studies to evaluate local ablative therapies for cancer including therapies guided by EUS and therapies applied during direct visualization of ducts. Some of these therapies include radiofrequency ablation, photodynamic therapy and brachytherapy.

Other developments are likely to include endoscopes with multimodal features and endoscopic platforms that permit even more precise localization of lesions by combining information from radiological procedures in addition to EUS (Roberts-Thomson et al., 2010). It would also be helpful to have better endoscopic therapy for calcific chronic pancreatitis. One option is fragmentation of stones under direct vision using electrohydraulic lithotripsy or various lasers including the yttrium-aluminium-garnet (YAG) laser. There is also a need for more sensitive techniques for the diagnosis of biliary and pancreatic neoplasms that might include larger tissue samples or the identification of novel proteins or novel gene mutations.

\section{Conclusion}

The biliary tract and pancreas have now been explored with flexible endoscopes for 40 years. The era of diagnostic procedures using an injection of radiological contrast and fluoroscopy was soon followed by the therapeutic procedure of endoscopic sphincterotomy for bile duct stones. Subsequent developments included plastic and metallic stents for biliary obstruction and endoscopic therapy for chronic pancreatitis and pancreatic pseudocysts. More recently, direct visualization of biliary and pancreatic ducts 
has become possible using ultrathin endoscopes passed down the channel of conventional endoscopes. A complementary procedure is that of endoscopic ultrasound that facilitates biliary and pancreatic diagnoses, particularly when combined with fine-needle aspiration and tissue cytology. Future developments are likely to include various endoscopic therapies for cancer and the wider use of endoscopic procedures for complications of pancreatitis .

\section{References}

Cahen, D. L., D. J. Gouma, Y. Nio, E. A. Rauws, M. A. Boermeester, O. R. Busch, J. Stoker, J. S. Lameris, M. G. Dijkgraaf, K. Huibregtse and M. J. Bruno (2007). "Endoscopic versus surgical drainage of the pancreatic duct in chronic pancreatitis." N Engl J Med 356: 676-84.

Chun, H. J., E. S. Kim, J. J. Hyun, Y. D. Kwon, B. Keum and C. D. Kim (2010). "Gastrointestinal and biliary stents." J Gastroenterol Hepatol 25: 234-43.

Classen, M. and L. Demling (1974). "[Endoscopic sphincterotomy of the papilla of vater and extraction of stones from the choledochal duct (author's transl)]." Dtsch Med Wochenschr 99: 496-7.

Cooper, S. T. and A. Slivka (2007). "Incidence, risk factors, and prevention of post-ERCP pancreatitis." Gastroenterol Clin North Am 36: 259-76, vii-viii.

DeWitt, J., C. J. DiMaio and W. R. Brugge (2011). "Long-term follow-up of pancreatic cysts that resolve radiologically after EUS-guided ethanol ablation." Gastrointest Endosc 72: 862-6.

Díte, P., M. Ruzicka, V. Zboril and I. Novotny (2003). "A prospective, randomized trial comparing endoscopic and surgical therapy for chronic pancreatitis." Endoscopy 35: 553-8.

Freeman, M. L., D. B. Nelson, S. Sherman, G. B. Haber, M. E. Herman, P. J. Dorsher, J. P. Moore, M. B. Fennerty, M. E. Ryan, M. J. Shaw, J. D. Lande and A. M. Pheley (1996). "Complications of endoscopic biliary sphincterotomy." N Engl J Med 335: 909-18.

Gleeson, F. C. and M. Topazian (2007). "Endoscopic retrograde cholangiopancreatography and endoscopic ultrasound for diagnosis of chronic pancreatitis." Curr Gastroenterol Rep 9: 123-9.

Hochberger, J., S. Tex, J. Maiss and E. G. Hahn (2003). "Management of difficult common bile duct stones." Gastrointest Endosc Clin N Am 13: 623-34.

Horwhat, J. D., E. K. Paulson, K. McGrath, M. S. Branch, J. Baillie, D. Tyler, T. Pappas, R. Enns, G. Robuck, H. Stiffler and P. Jowell (2006). "A randomized comparison of EUS-guided FNA versus CT or US-guided FNA for the evaluation of pancreatic mass lesions." Gastrointest Endosc 63: 966-75.

Howell, D. A., W. G. Parsons, M. A. Jones, J. J. Bosco and B. L. Hanson (1996). "Complete tissue sampling of biliary strictures at ERCP using a new device." Gastrointest Endosc 43: 498-502.

Kawai, K., Y. Akasaka, K. Murakami, M. Tada and Y. Koli (1974). "Endoscopic sphincterotomy of the ampulla of Vater." Gastrointest Endosc 20: 148-51. 
Kim, Y. S., K. Gupta, S. Mallery, R. Li, T. Kinney and M. L. Freeman (2010). "Endoscopic ultrasound rendezvous for bile duct access using a transduodenal approach: cumulative experience at a single center. A case series." Endoscopy 42: 496-502.

Kondo, S., H. Isayama, M. Akahane, N. Toda, N. Sasahira, Y. Nakai, N. Yamamoto, K. Hirano, Y. Komatsu, M. Tada, H. Yoshida, T. Kawabe, K. Ohtomo and M. Omata (2005). "Detection of common bile duct stones: comparison between endoscopic ultrasonography, magnetic resonance cholangiography, and helical-computedtomographic cholangiography." Eur J Radiol 54: 271-5.

Lutz, H. and W. Rosch (1976). "Transgastroscopic ultrasonography." Endoscopy 8: 203-5.

McCune, W. S., P. E. Shorb and H. Moscovitz (1968). "Endoscopic cannulation of the ampulla of vater: a preliminary report." Ann Surg 167: 752-6.

Mergener, K. and R. A. Kozarek (2003). "Therapeutic pancreatic endoscopy." Endoscopy 35: 48-54.

Mohamadnejad, M., J. M. DeWitt, S. Sherman, J. K. LeBlanc, H. A. Pitt, M. G. House, K. J. Jones, E. L. Fogel, L. McHenry, J. L. Watkins, G. A. Cote, G. A. Lehman and M. A. Al-Haddad (2011). "Role of EUS for preoperative evaluation of cholangiocarcinoma: a large single-center experience." Gastrointest Endosc 73: 71-8.

Nguyen, N. and K. Binmoeller (2009). Endoscopic drainage of pancreatic fluid collections. Diagnostic and Therapeutic Procedures in Gastroenterology: An Illustrated Guide. A. Wu, and Varadarajulu, Humana Press: 211-221.

Nguyen, N. and K. Binmoeller (2010). "Endoscopic ampullectomy." Journal of Techniques in GI Endoscopy 12: 53-60.

Nguyen, N. Q., K. F. Binmoeller and J. N. Shah (2009). "Cholangioscopy and pancreatoscopy (with videos)." Gastrointest Endosc 70: 1200-10.

Oh, H. C., D. W. Seo, T. J. Song, S. H. Moon, H. Park do, S. Soo Lee, S. K. Lee, M. H. Kim and J. Kim (2011). "Endoscopic ultrasonography-guided ethanol lavage with paclitaxel injection treats patients with pancreatic cysts." Gastroenterology 140: 172-9.

Petersen, B. T. (2002). "ERCP outcomes: defining the operators, experience, and environments." Gastrointest Endosc 55: 953-8.

Roberts-Thomson, I. C. (1984). "Endoscopic sphincterotomy of the papilla of Vater: an analysis of 300 cases." Aust N Z J Med 14: 611-7.

Roberts-Thomson, I. C., R. Singh, E. Teo, N. Q. Nguyen and I. Lidums (2010). "The future of endoscopy." J Gastroenterol Hepatol 25: 1051-7.

Safrany, L. (1978). "Endoscopic treatment of biliary-tract diseases. An international study." Lancet 2: 983-5.

Soehendra, N. and V. Reynders-Frederix (1979). "[Palliative biliary duct drainage. A new method for endoscopic introduction of a new drain]." Dtsch Med Wochenschr 104: 206-7.

Takagi, K., S. Ikeda, Y. Nakagawa, N. Sakaguchi and T. Takahashi (1970). "Retrograde pancreatography and cholangiography by fiber duodenoscope." Gastroenterology 59: 445-52.

Tanaka, K. and M. Kida (2009). "Role of endoscopy in screening of early pancreatic cancer and bile duct cancer." Dig Endosc 21 Suppl 1: S97-S100. 
van der Gaag, N. A., E. A. Rauws, C. H. van Eijck, M. J. Bruno, E. van der Harst, F. J. Kubben, J. J. Gerritsen, J. W. Greve, M. F. Gerhards, I. H. de Hingh, J. H. Klinkenbijl, C. Y. Nio, S. M. de Castro, O. R. Busch, T. M. van Gulik, P. M. Bossuyt and D. J. Gouma (2009). "Preoperative biliary drainage for cancer of the head of the pancreas." N Engl J Med 362: 129-37. 


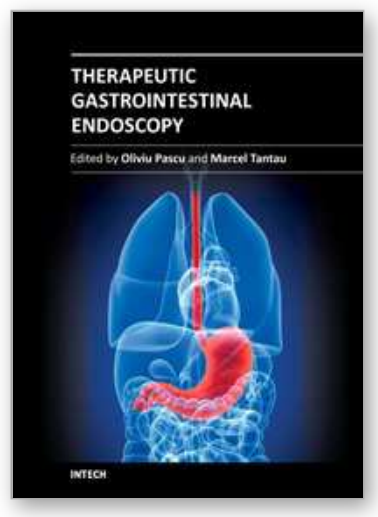

\author{
Therapeutic Gastrointestinal Endoscopy \\ Edited by Prof. Oliviu Pascu
}

ISBN 978-953-307-743-7

Hard cover, 216 pages

Publisher InTech

Published online 22, September, 2011

Published in print edition September, 2011

Endoscopy has had a big role in the development of modern gastroenterology. Modern endoscopy will certainly be more therapeutic. It started with endoscopic hemostasis and polipectomy, than beginning of the 1970 's with the advent of endoscopic sphincterotomy extended to biliopancreatic pathology and has a huge impact in this difficult pathology. Plastic stents made the first steps in endoscopic palliation of neoplastic jaundice, metallic stents, covered or uncovered are better for biliary palliation and can be used also for palliation neoplastic obstruction at different levels of the digestive tube. Resection of digestive tumors has evolved now to sub-mucosal resection, looking to have one-piece complete resection. Interventional endoscopy is now very complex and takes a lot of time for endoscopists to learn properly these techniques. This book is a very good up-to-date overview of new techniques of interventional endoscopy for those who want to learn or develop their knowledges in this field.

\title{
How to reference
}

In order to correctly reference this scholarly work, feel free to copy and paste the following:

Ian C Roberts-Thomson and Nam Q Nguyen (2011). Diagnostic and Therapeutic Endoscopy in the Biliary Tract and Pancreas, Therapeutic Gastrointestinal Endoscopy, Prof. Oliviu Pascu (Ed.), ISBN: 978-953-307743-7, InTech, Available from: http://www.intechopen.com/books/therapeutic-gastrointestinalendoscopy/diagnostic-and-therapeutic-endoscopy-in-the-biliary-tract-and-pancreas 1

\section{INTECH}

open science | open minds

\section{InTech Europe}

University Campus STeP Ri

Slavka Krautzeka 83/A

51000 Rijeka, Croatia

Phone: +385 (51) 770447

Fax: +385 (51) 686166

www.intechopen.com

\section{InTech China}

Unit 405, Office Block, Hotel Equatorial Shanghai

No.65, Yan An Road (West), Shanghai, 200040, China 中国上海市延安西路65号上海国际贵都大饭店办公楼 405 单元

Phone: +86-21-62489820

Fax: $+86-21-62489821$ 
(C) 2011 The Author(s). Licensee IntechOpen. This chapter is distributed under the terms of the Creative Commons Attribution-NonCommercialShareAlike-3.0 License, which permits use, distribution and reproduction for non-commercial purposes, provided the original is properly cited and derivative works building on this content are distributed under the same license. 